\title{
CORTE SUPREMA. ROL No 9.858-2013. RECURSO DE UNIFICACIÓN DE JURISPRUDENCIA (ArTículos 183-B y 183-E del Código del Trabajo)
}

\author{
ROBERTo Cerón ReYes*
}

\section{INTRODUCCIÓN}

La Ley $N^{\circ} 16.744$ de 1 de febrero de 1968, sobre Seguro Obligatorio por Accidentes del Trabajo y Enfermedades Profesionales, instituyó en nuestro país un seguro social en caso de que a un trabajador le ocurriese un accidente del trabajo o sufriese una enfermedad profesional. A juicio de la doctrina autorizada, tal marco regulatorio no constituye en sí un régimen especial de responsabilidad civil ${ }^{1}$. Como advierte el profesor Zelaya: "[L]a responsabilidad civil es una institución de derecho privado que tiene por finalidad determinar -a través de un proceso judicial que incluye una calificación jurídica normativa de los hechos probadosqué patrimonio soportará, en definitiva, el peso económico del daño causado o sufrido por una víctima inocente, en cambio, la Seguridad Social es una institución de derecho público mediante la cual el Estado pretende proteger a ciertas personas, más débiles y desprotegidas, mediante, prestaciones asistenciales automática y tarificadas, sin que necesariamente deba existir un criterio jurídico de imputación del deber de reparar" 2 .

Sin perjuicio de lo anterior, la propia ley en asunto estableció en su artículo 69 letra b) que: "Cuando el accidente o enfermedad se deba a culpa o dolo de la entidad empleadora o de un tercero... la víctima y las

Instructor, Facultad de Derecho, Universidad de Chile (CHILE). Correo electrónico: roberto.ceron@derecho.uchile.cl

1 Sobre el punto véase Domínguez Águila, Ramón (2005): "Responsabilidad civil y Seguridad Social". En: Baraona González, Jorge; Zelaya Etchegaray, Pedro (editores): La responsabilidad por accidentes del trabajo. Cuadernos de Extensión Jurídica $\mathrm{N}^{\circ} 10$. Santiago: Universidad de los Andes, Facultad de Derecho, pp. 23-43. Zelaya Etchegaray, Pedro (2005): "La responsabilidad subsidiaria del dueño de obra por los accidentes y daños experimentados por el trabajador del contratista”. En: Baraona González, Jorge; Zelaya Etchegaray, Pedro (editores): La responsabilidad por accidentes del trabajo. Cuadernos de Extensión Jurídica $\mathrm{N}^{\circ}$ 10. Santiago: Universidad de los Andes, Facultad de Derecho, pp. 99-122, p. 102. Este último autor profundiza dicha idea en su texto "La responsabilidad solidaria de la empresa principal frente a los dańos experimentados por el trabajador del contratista". Revista de Derecho y Jurisprudencia. Tomo CIII, $\mathrm{N}^{\circ}$ 1, pp. 1-29, pp. 3-4. 
demás personas a quienes el accidente o enfermedad cause daño podrán reclamar al empleador o terceros responsables del accidente, también las indemnizaciones a que tengan derecho con arreglo a las prescripciones del derecho común, incluso del daño moral", de modo tal que a causa de un accidente o enfermedad profesional puede surgir, también, una acción civil indemnizatoria, la cual se rige por las "prescripciones del derecho común", vale decir, por las normas de la responsabilidad civil contractual o extracontractual ${ }^{3}$.

El ordenamiento jurídico-laboral chileno, a través de la Ley $\mathrm{N}^{\circ}$ 20.123 de 16 de octubre de 2006, reguló e incorporó al Código del Trabajo (en adelante CT) en su Libro I-Título VI, "[D]el trabajo en régimen de subcontratación y [D]el trabajo en empresas de servicios transitorios", derogando, a propósito del primero de estos regímenes, los artículos 64 y 64 bis del CT. En materia de accidentes del trabajo, la normativa de referencia incorporó el artículo $183 \mathrm{E}$ que establece un deber de protección para la empresa principal respecto de todos los trabajadores que laboran en su obra, empresa o faena, cualquiera sea su dependencia ${ }^{4}$. Asimismo, el artículo 183 B consagró la solidaridad de la empresa principal respecto de las obligaciones laborales y previsionales de dar, que afecten a los contratistas en favor de los trabajadores de estos, así como de las eventuales indemnizaciones legales que correspondan por término de la relación laboral ${ }^{5}$.

3 Cuestión que ha dado pie a la doctrina para hablar de un "cúmulo restringido de acciones" o, derechamente, de un "cúmulo de acciones". Zelaya (Tomo CIII) 4. Corral Talciani, Hernán (2010). "Concurrencia de acciones de responsabilidad civil contractual y extracontractual en los daños causados por accidentes del trabajo". Revista Chilena de Derecho Privado, $\mathrm{N}^{\circ} 14$, pp. 69-107, pp. 6-12 (del artículo).

4 Articulo 183-E. Sin perjuicio de las obligaciones de la empresa principal, contratista y subcontratista respecto de sus propios en virtud de lo dispuesto en el artículo 184, la empresa principal deberá adoptar las medidas necesarias para proteger eficazmente la vida y salud de todos los trabajadores que laboran en su obra, empresa o faena, cualquiera sea su dependencia, en conformidad a lo dispuesto en el artículo 66 bis de la Ley $N^{\circ} 16.744$ y el artículo $3^{\circ}$ del Decreto Supremo $N^{\circ}$ 594, de 1999, del Ministerio de Salud.

5 Art. 183-B. La empresa principal será solidariamente responsable de las obligaciones laborales $y$ previsionales de dar que afecten a los contratistas en favor de los trabajadores de éstos, incluidas las eventuales indemnizaciones legales que correspondan por término de la relación laboral. Tal responsabilidad estará limitada al tiempo o periodo durante el cual el o los trabajadores prestaron servicios en régimen de subcontratación para la empresa principal.

En los mismos términos, el contratista será solidariamente responsable de las obligaciones que afecten a sus subcontratistas, a favor de los trabajadores de éstos.

La empresa principal responderá de iguales obligaciones que afecten a los subcontratistas, cuando no pudiere hacerse efectiva la responsabilidad a que se refiere el inciso siguiente.

El trabajador, al entablar la demanda en contra de su empleador directo, podrá hacerlo en contra de todos aquellos que puedan responder de sus derechos, en conformidad a las normas de este Párrafo.

En los casos de construcción de edificaciones por un precio único prefijado, no procederán estas responsabilidades cuando quien encargue la obra sea una persona natural. 
Frente a los diferentes pronunciamientos de los tribunales de justicia sobre la naturaleza de la obligación indemnizatoria de daño moral por accidente del trabajo y la aplicación a dicho resarcimiento, de la solidaridad, del artículo $183 \mathrm{~B}^{6}$, la Corte Suprema de Justicia, a través de recurso de unificación de jurisprudencia, sentó la correcta interpretación de los artículos 183 B y 183 E; decisión que ahora se examinará.

\section{1) DECISIÓN DEL CASO Y COMENTARIOS}

\section{1) BREVE DESCRIPCIÓN DEL CASO}

Carmelo Aguayo San Martín, trabajador de la empresa contratista Ingeniería y Construcciones Osarco E.I.R.L., víctima de un accidente del trabajo, dedujo acción de indemnización de perjuicios en contra de la empresa antes dicha y solidariamente respecto del dueño de la obra donde se encontraba prestando servicios: Codelco Chile, División Codelco Norte. El Juzgado de Letras del Trabajo de Calama, conociendo de la acción y por sentencia definitiva de nueve de mayo de dos mil trece, acogió la demanda y condenó solidariamente a las demandadas a pagar sendas sumas de dinero por concepto de indemnización por daño emergente y moral.

En contra de la referida sentencia, la demandada solidaria interpuso ante la Corte de Apelaciones de Antofagasta, recurso de nulidad invocando la causal del artículo $477^{7}$ del CT, en relación con los artículos 183

6 El propio recurrente señala los siguientes pronunciamientos: Corte de ApelaCiones DE Santiago (Sala Trabajo-menores-policía local). 29 de febrero de 2012. Rol N 68-2012. "Fuenzalida Villalobos Pedro/Polymont Chile S.A.". Disponible en http://corte.poderjudicial. cl/SITCORTEPORWEB/ [fecha de visita 25 de agosto de 2014]. Corte Suprema (Unificación de jurisprudencia). 27 de marzo de 2013. Rol No 5620-2012. "Ramírez con Mena". Disponible en http://suprema.poderjudicial.cl/SITSUPPORWEB/InicioAplicacion.do [fecha de visita 25 de agosto de 2014]. Dicha sentencia fue objeto de un comentario de jurisprudencia por parte del profesor Marcelo Barrientos Zamorano (2013). "Sentencia de unificación sobre responsabilidad de la empresa principal en accidentes del trabajo subcontratado". Revista Chilena de Derecho, vol. 40, N³, pp. 1001-1016. Asimismo cabría agregar Corte de Apelaciones de Santiago (Reforma Laboral). 20 de junio de 2012. Rol N ${ }^{\circ}$ 847-2011. Disponible en http://corte.poderjudicial.cl/SITCORTEPORWEB/ [fecha de visita 25 de agosto de 2014]. Corte de Apelaciones de La Serena. 7 de diciembre de 2010. $\mathrm{N}^{\circ}$ LegalPublishing: 46933. Sobre las materias que han sido objeto de recurso de unificación de jurisprudencia véase Soto Bustos, Samuel (2013). “¿Criterios unificados como precedentes judiciales en materia laboral? (Revisión crítica de los fallos que acogen el recurso de unificación laboral entre marzo de 2008 y agosto de 2013". Revista de Estudios de la Justicia, $\mathrm{N}^{\circ}$ 19, pp. 215-255 y Poder Judicial (2014). Doctrina establecida por la Corte Suprema en materia laboral a través de los recursos de unificación de jurisprudencia acogidos entre 2011 a junio 2014. Santiago: Corte Suprema, Dirección de Estudio, Análisis y Evaluación, Informe $\mathrm{N}^{\circ} 33-2014,39$ pp.

7 Art. 477. Tratándose de las sentencias definitivas, solo será procedente el recurso de nulidad, cuando en la tramitación del procedimiento o en la dictación de la sentencia definitiva se hubie- 
$\mathrm{E}^{8}, 184^{9}$ y $183 \mathrm{~B}^{10}$ del mismo código, además de las causales previstas en las letras a) y c) del artículo $478^{11}$ del precitado cuerpo legal. La Corte, por sentencia de 15 de julio de 2013, lo rechazó. En contra de esta última sentencia, la demandada dedujo recurso de unificación de jurisprudencia solicitando al máximo tribunal que lo acogiese y dictase la correspondiente sentencia de reemplazo, declarando que no procedía condenar solidariamente a la empresa principal por las indemnizaciones de perjuicios de daño emergente y daño moral en razón de accidente del trabajo, el cual fue acogido por sentencia de 25 de febrero de 2014.

\section{2) SOBRE LAS DISTINTAS INTERPRETACIONES}

Es conveniente exponer las diferentes interpretaciones dadas por la jurisprudencia a los artículos 183 B y 183 E del CT, algunas de las cuales son invocadas por el demandado solidario para fundar su recurso.

\subsection{1) Corte de Apelaciones de Antofagasta}

El tribunal de referencia, por sentencia de nulidad, sostiene que:

"[...] tratándose de las indemnizaciones de perjuicios por accidente del trabajo, la responsabilidad del dueño de la obra o faena surge en la medida que este no haya ejercido la prerrogativa de fiscalizar la adopción de las medidas de seguridad necesarias a que está obligado el contratante directo del trabajador, todo ello de conformidad a lo dispuesto por el artículo 184 del Código del Trabajo, en relación a lo dispuesto en los artículos 183 B y 183 E de ese cuerpo legal. Esta omisión lo hace responsable de los perjuicios que un accidente laboral haya causado al trabajador, debiendo, además, establecerse que el deber de seguridad del empleador es de aquellos al que hace refe-

ren infringido sustancialmente derechos o garantías constitucionales, o aquélla se hubiere dictado con infracción de ley que hubiere influido sustancialmente en lo dispositivo del fallo. En contra de las sentencias definitivas no procederán más recursos.

El recurso de nulidad tendrá por finalidad invalidar el procedimiento total o parcialmente junto con la sentencia definitiva, o solo esta última, según corresponda.

$8 \quad$ Ver nota 4.

$9 \quad$ Art. 184. El empleador estará obligado a tomar todas las medidas necesarias para proteger eficazmente la vida y salud de los trabajadores, informando de los posibles riesgos y manteniendo las condiciones adecuadas de higiene y seguridad en las faenas, como también los implementos necesarios para prevenir accidentes y enfermedades profesionales...

$10 \quad$ Ver nota 5.

11 Art. 478. El recurso de nulidad procederá, además:

a) Cuando la sentencia haya sido pronunciada por juez incompetente, legalmente implicado, o cuya recusación se encuentre pendiente o haya sido declarada por tribunal competente;

c) Cuando sea necesaria la alteración de la calificación jurídica de los hechos, sin modificar las conclusiones fácticas del tribunal inferior; 
rencia el artículo 69 de la Ley 16.744, sobre accidentes del Trabajo... [además] el artículo $183 \mathrm{~B}$ del Código laboral dispone que la empresa principal será solidariamente responsable de las obligaciones laborales y previsionales de dar que afecten a los contratistas a favor de sus trabajadores. A su vez, el inciso segundo establece la solidaridad del contratista respecto de las obligaciones que afecten a los subcontratistas y a favor de los trabajadores de estos. Asimismo, el artículo 183 E del citado Código dispone que el deber de protección de la vida y salud de los trabajadores se extiende a la empresa principal respecto de los trabajadores de la empresa contratista o subcontratista, quien deberá adoptar las medidas necesarias para cumplir con dicha obligación respecto de todos los trabajadores que laboran en su obra, empresa o faena. De ello se concluye que la empresa principal tiene responsabilidad respecto a las obligaciones que afectan a subcontratistas en relación a sus dependientes y específicamente sobre el deber de protección"12.

Se advierte del razonamiento transcrito que la Corte estimó que la responsabilidad de la empresa principal, en materia de accidente del trabajo, se origina siempre y cuando esta no haya fiscalizado al contratista en la adopción de medidas de seguridad para con sus trabajadores, de acuerdo a lo prescrito en el artículo 184 del CT. A su vez, de manera vaga y sin mediar razonamiento alguno, relacionó los artículos 183 B y $183 \mathrm{E}$, ambos del CT, no explicando el ámbito de aplicación de cada precepto. Termina estableciendo la responsabilidad solidaria de la empresa principal respecto de las "obligaciones" - sin decir de qué naturaleza- que "afectan a subcontratistas en relación a sus dependientes y específicamente el deber de protección".

\subsection{2) Corte de Apelaciones de La Serena}

En la misma línea, aunque con algunas diferencias, la Corte razona lo siguiente:

"El artículo 184 del Código del Trabajo impone al empleador la obligación de tomar las medidas necesarias para proteger eficazmente la vida y salud de los trabajadores, informando de los posibles riesgos y manteniendo las condiciones adecuadas de higiene y seguridad en las faenas, como también de los implementos necesarios para evitar accidentes y enfermedades profesionales. Por su parte el artículo $183 \mathrm{E}$ del mismo Código dispone que la empresa principal deberá adoptar las medidas de seguridad respecto de los trabajadores para proteger

12 Ver nota 11. 
eficazmente la vida y salud de estos que laboran en su obra, empresa o faena, cualquiera sea su dependencia... En consecuencia, tanto el contratista como la empresa principal -dueña de la obra- tienen la obligación de deber y cuidado, respecto de la seguridad de sus trabajadores, responsabilidad que tiene el carácter de solidaria. Resulta errado, entonces, restringir la responsabilidad solidaria del dueño de la obra solo a las obligaciones de dar. De los artículos 183 B y 183 E del Código del Trabajo se desprende que, ante el incumplimiento de la obligación de seguridad por parte del contratista y de la empresa principal, existe una pluralidad de obligados para con un mismo acreedor, siendo el objeto debido uno mismo: la indemnización del daño producido como consecuencia del accidente laboral. El acreedor tiene dos deudores y hay solidaridad entre ellos, porque la ley a pesar de establecer la responsabilidad directa del dueño de la obra, lo hace solidario de las obligaciones laborales que afecten al contratista...".

El tribunal estableció que el deber de protección del contratista respecto de sus trabajadores, emana del artículo 184 del CT, mientras que la empresa principal tiene ese igual deber para los mismos destinatarios, pero fundado en el artículo $183 \mathrm{E}$ del mismo código. En consecuencia, ambos tienen su propio deber de protección y cuidado. Frente a un incumplimiento de la contratista y de la empresa principal, les atribuyó una responsabilidad solidaria, pues le otorgó un alcance amplio a la solidaridad contenida en el artículo 183 B del CT, sin distinguir entre obligaciones de dar y hacer.

\subsection{3) Decisión del tribunal a quo}

El Juzgado de Letras del Trabajo de Calama establece que en el trabajo en régimen de subcontratación:

"Específicamente la responsabilidad de la empresa mandante ante incumplimiento de la empresa contratista, alcanza también a la responsabilidad por accidentes del trabajo, pues no se está haciendo responsable directo a la empresa mandante ante una eventual falta de control o negligencia de su parte, sino que se está aplicando el artículo 183 B del Código del Trabajo, en cuanto asegura al trabajador otro patrimonio donde hacer efectivo sus créditos laborales en caso incumplimiento del empleador, la empresa contratista [...] Por otra parte, el pago de una obligación derivada de un accidente del trabajo, no es una obligación de hacer, sino que es ciertamente una obligación de dar, pagar una suma de dinero, tanto así que nada impide que repita posteriormente contra el principal obligado que resulta ser la empresa empleadora. De esta manera, no se advierten fundamen- 
tos reales y consistentes para dejar fuera de la obligación a la demandada solidaria, de manera que se declarará su responsabilidad en la obligación surgida del accidente del trabajo"13.

El raciocinio del tribunal descansó en torno a la responsabilidad que le cabría a la empresa principal, ante el incumplimiento de la empresa contratista en materia de accidentes del trabajo, que por aplicación del artículo 183 B del CT, sería solidaria. Se pronunció sobre la naturaleza de la obligación derivada de un accidente del trabajo, calificándola de dar y no de hacer.

\subsection{4) Corte de Apelaciones de Santiago y Corte Suprema}

Por otra parte, el tribunal de alzada de la capital, por sentencia de 29 de febrero de 2012 y la Corte Suprema, por sentencia de recurso de unificación de 27 de marzo de 2013, sostuvieron una línea jurisprudencial diversa. La primera concluyó que "la responsabilidad solidaria no puede extenderse a la obligación de hacer que pesa sobre el empleador directo [artículo $184 \mathrm{CT}$ ], de tal forma que al ser esta última obligación la que resulta incumplida, no puede hacerse responsable solidaria a la empresa principal"14, mientras que el máximo tribunal sentenció que "la responsabilidad de la empresa principal, tratándose de accidentes del trabajo, es directa en el caso de incumplir el deber de protección que el mismo texto del artículo $183 \mathrm{E}$ del Código del Trabajo le impone, de modo que al hacer aplicable al caso el artículo 183 E y no el artículo $183 \mathrm{~B}$, no se incurrió en infracción de ley en la sentencia impugnada por el recurso de nulidad" 15 .

De las argumentaciones de ambos tribunales se desprende que la empresa principal no respondió solidariamente de un incumplimiento del contratista, derivado del artículo 184 del CT. Por su parte, en materia de accidentes del trabajo, la responsabilidad de la empresa principal fue directa y se fundó en el artículo $183 \mathrm{E}$ del CT, no aplicándose lo estatuido en el artículo $183 \mathrm{~B}$ del CT.

En síntesis, de la sola lectura de las sentencias reseñadas se deduce la existencia de diferentes interpretaciones en torno a los artículos $183 \mathrm{~B}$ y 183 E del CT. Se entiende entonces, que a la luz de la jurisprudencia acompańada por el recurrente, la Corte estimara admisible el recurso interpuesto.

\footnotetext{
13 Considerando Segundo de la sentencia de unificación. Considerando Segundo de la sentencia de unificación. Considerando Segundo de la sentencia de unificación.
} 


\section{3) DECISIÓN DEL ASUNTO}

Ante las diferentes interpretaciones de los tribunales a los artículos 183 B y 183 E del CT, la Corte decidió unificar la materia, particularmente en lo que dice relación con la naturaleza de la obligación indemnizatoria del daño moral por accidente del trabajo y la aplicación a dicho resarcimiento, de la solidaridad establecida en el primer precepto citado. En una decisión acertada, pero carente de fundamentos dogmáticos sólidos, dictó sentencia de reemplazo acogiendo la causal del artículo 477 del $\mathrm{CT}^{16}$. En síntesis, indicó que:

“[...] no obstante, que los textos de los artículos 183 B y 183 D del Código del Trabajo establecen respecto del dueño de la obra una responsabilidad por garantía en relación con las obligaciones laborales y previsionales de dar que debe satisfacer el empleador respecto de sus trabajadores, erigiendo a aquél en responsable solidario o subsidiario según se hubiere cumplido o no con las exigencias previstas por la última norma citada -y acotadas estas obligaciones en la forma que explicitan esos textos-, lo cierto es que tratándose de un accidente del trabajo la ley reguló la situación imponiendo a la empresa principal (dueña de la obra) un deber de protección especial en el artículo 183 E del Código del ramo, deber que se expresa en similares términos a aquél que el artículo 184 impone al empleador contratista o subcontratista... Que lo expuesto en los considerandos que anteceden conduce a concluir que la sentencia impugnada por el recurso de nulidad, ha incurrido en infracción de ley al considerar que, en la situación del demandante, es aplicable la norma del artículo $183 \mathrm{~B}$ del Código del ramo y no el artículo $183 \mathrm{E}$ del mismo cuerpo legal, que dispone que la responsabilidad de la empresa principal en un accidente del trabajo solo puede ser declarada en virtud de un incumplimiento de las obligaciones propias y particulares que la ley le ha impuesto sobre la materia y no como garante de las obligaciones que ha debido cumplir el empleador directo... Que, en consecuencia, se unifica la jurisprudencia en el sentido anotado en los motivos anteriores, esto es, que la empresa principal no es responsable solidaria sino directa en el cumplimiento de la obligación de seguridad en relación con los trabajadores que se desempeñen en sus obras o faenas" ${ }^{17}$.

16 Nos llama la atención que no haya acogido la causal del artículo 478 letra a) del CT, por las razones que desarrollaremos en el punto 1.5 de este comentario.

17 Considerandos Segundo, Cuarto, Quinto y Séptimo de la sentencia de reemplazo. Cabe advertir al lector que la Corte Suprema volvió a unificar los artículos 183-B y 183-E del Código del Trabajo. En efecto, y a propósito de la indemnización por daño moral por accidente de trabajo, señaló la procedencia del estatuto de la solidaridad entre la empresa principal y el contratista, en atención a los esenciales principios que inspiran al derecho del trabajo; así como la naturaleza de esta obligación indemnizatoria, que a juicio del tribunal, sería de 


\section{4.) Comentarios}

En primer lugar, del sucinto razonamiento del tribunal se desprende una correcta interpretación del artículo 183 B que establece una responsabilidad solidaria "por garantía" respecto de las obligaciones laborales y previsionales de "dar". Planteamiento que se condice con la posición de la doctrina que entiende que la responsabilidad subsidiaria o solidaria de la empresa principal -según se ejerza la facultad del artículo 183 C- actúa como una garantía patrimonial para los trabajadores respecto de las obligaciones laborales y previsionales de "dar", no extendiéndose a las obligaciones indemnizatorias por daños imputables a dolo o culpa del contratista $^{18}$, como sería la infracción al deber de seguridad que tiene sobre sus propios trabajadores, según lo dispuesto en el artículo 184 del CT; puesto que ello constituiría una obligación de hacer que escapa al alcance objetivo del artículo 183 B del CT, así como también todas las obligaciones de hacer y las de dar derivadas del cumplimiento por equivalencia de las obligaciones de hacer, y las obligaciones de origen contractual que únicamente gravan el patrimonio del empleador directo ${ }^{19}$.

A mayor abundamiento, la propia historia de la ley ${ }^{20}$ y la jurisprudencia administrativa ${ }^{21}$ se pronuncian en el mismo sentido propuesto por la doctrina.

En segundo lugar, también se estima adecuado el alcance dado por la Corte al artículo $183 \mathrm{E}$ del CT. En efecto, el deber de protección de la empresa principal respecto de los trabajadores que prestan servicios en su faena, es una obligación directa y subjetiva que le impone el mencionado

aquellas de dar. Ambas decisiones muy controvertidas, por los argumentos que exponemos a lo largo de este comentario. Corte Suprema. 10 de junio de 2014. Rol N 10139-2013. "José Enrique Molina Aguilera con Comercial Sepmo y Cía. Ltda. Orizon S.A.". Disponible en http://suprema.poderjudicial.cl/SITSUPPORWEB/InicioAplicacion.do [fecha de visita 25 de agosto de 2014].

18 Zelaya (Tomo CIII) 23. Una postura crítica sobre el punto se encuentra en Palavecino CÁceres, Claudio (2006) Subcontratación. Régimen jurídico del trabajo subcontratado y del suministro de personal. Santiago: Editorial Jurídica de Chile, 121 pp., pp. 58-59.

19 Palavecino (2006) 69-70. Lizama Portal, Luis; Ugarte Cataldo, José Luis (2007) Subcontratación y suministro de trabajadores. Santiago: LexisNexis, 167 pp., p. 39. CorraL (2010) 16. Lanata Fuenzalida, Ruth Gabriela (2011) El Derecho Civil en el Derecho del Trabajo. Tesis doctoral Universidad de Rosario (inédita). 716 pp., pp. 322-323. Agradezco a la autora el ejemplar obsequiado. BARrientos (2013) 1006-1007.

20 La historia del artículo $183-\mathrm{B}$ es clara en este punto "Se discutió ampliamente durante la tramitación del Proyecto, cuál sería el alcance de las obligaciones de las que respondería solidaria o subsidiariamente la empresa principal. Se adujo por el Subsecretario del Trabajo, que el proyecto en cuestión no alteraba las reglas ya vigentes en esta materia, en el sentido que habían sido entendidas por la jurisprudencia, vale decir, solo se responde por las obligaciones de "dar" y no por las de "hacer". CAAmaño Rojo, Eduardo (Director) (2012) Código del Trabajo. 2 tomos. Santiago: Editorial LegalPublishing, 1337 pp., p. 333 (1).

Dirección del Trabajo. Dictamen No 141/05, de 10 de enero de 2007. 
artículo, aspecto ampliamente validado por la doctrina ${ }^{22}$. De este modo, resulta cuestionable sostener que en este punto, la empresa principal es garante de la obligación del empleador directo, establecida en el artículo 184 del CT, ya que sobre ella pesa una misma y propia obligación, pero cuya fuente es el artículo 183 E del CT. De esta manera, únicamente a raíz de un incumplimiento propio, imputable a culpa o dolo, podrá incurrir en responsabilidad civil.

\section{5) Otras CUESTiOnes ATINGENTES AL CASO}

Sin embargo, la sentencia que se comentó al fijar la correcta interpretación de los artículos 183 B y 183 E del CT, no se pronunció sobre dos importantes cuestiones que guardan relación con el último precepto citado. Si bien la Corte establece que el artículo 183 E del CT impone a la empresa principal una obligación directa y subjetiva, nada dice respecto de cuál sería el estatuto de responsabilidad civil -contractual o extracontractual- aplicable en caso de infringir dicho deber. En mi opinión y siguiendo a un importante sector de la doctrina, creo que es el extracontractual $^{23}$, ya que no existe un vínculo jurídico entre la empresa principal y los trabajadores de la contratista. En este sentido, el artículo $183 \mathrm{E}$ impone un "especial deber de cuidado" 24 a la empresa principal que en caso de infringirse, expone a aquélla a las indemnizaciones derivadas de la responsabilidad aquiliana.

Lo anterior conduce al segundo aspecto no abordado por la sentencia, que dice relación con la eventual incompetencia de los tribunales laborales para conocer del incumplimiento de la empresa principal, respecto de la obligación del artículo $183 \mathrm{E}$ del CT. Los tribunales del trabajo, al no existir ningún vínculo contractual entre aquella y los trabajadores del empleador directo, no pueden conocer de tales asuntos, por lo dispuesto en el artículo 420 letra f) del CT que en lo pertinente expresa “...con excepción de la responsabilidad extracontractual a la cual le será aplicable lo dispuesto en el artículo 69 de la Ley $\mathrm{N}^{\circ}$ 16.744”, lo que obliga al trabajador a interponer su acción en contra de la empresa principal ante los tribunales ordinarios de justicia. Así, debe probar la culpa o dolo de la empresa principal, la prueba se valora según las normas del procedimiento civil -legal y tasado- y no las del procedimiento laboral -según la

22 Palavecino (2006) 72. Zelaya (Tomo CIII) 27. Lizama; Ugarte (2007), 50-52. Diez Schwerter, José Luis (2008). "Responsabilidad civil derivada de accidentes del trabajo y enfermedades profesionales: aspectos relevantes de su regulación y operatoria actual”. Revista de Derecho Pontificia Universidad Católica del Norte. N ${ }^{\circ} 31$, pp. 163-185, pp. 171-172. Corral (2010) 17. Lanata (2011) 345 y ss. Barrientos (2013) 1006-1007.

23 Diez (2008) 174-176 quien solo se limita a exponer la posición. Corral (2010) 18-19. LANATA (2011) 348 y ss.

$24 \quad$ Zelaya (Tomo CIII) 27. 
sana crítica-. Por ende, tampoco se aplican los principios que inspiran a la disciplina jurídico-laboral, entre otros aspectos ${ }^{25}$. En este punto creo, al igual que el profesor Corral, "que no parece conveniente que la responsabilidad extracontractual del dueño de la obra sea sustanciada ante un juez y con un procedimiento distinto del que corresponde a la responsabilidad del empleador directo. Pero esto es una consecuencia de no haberse modificado el art. 420 letra f) del Código del Trabajo, que puede ser criticado, pero no ignorado en su claro tenor y sentido literal" 26 .

De haberse acogido el recurso por la infracción al artículo 478 letra a) del CT -incompetencia del tribunal- estas dos prevenciones habrían sido innecesarias, pues formarían parte de la sentencia que se comentó.

\section{CONCLUSIONES}

1. De acuerdo a lo previsto en el artículo 483 del CT, contra la resolución que falle el recurso de nulidad, podrá interponerse recurso de unificación de jurisprudencia, el cual es conocido por la Corte Suprema cuando respecto de la materia de derecho, objeto del juicio, existieren distintas interpretaciones.

2. La Corte Suprema ante las diversas interpretaciones dadas a los artículos 183 B y $183 \mathrm{E}$ del CT, específicamente la naturaleza de la obligación indemnizatoria de dańo moral por accidente del trabajo y la aplicación a dicho resarcimiento, de la solidaridad contenida en la primera de las disposiciones citadas, ha fijado una orientación de tales preceptos, lo que no impide que el máximo tribunal reinterprete en un sentido distinto dichas disposiciones ${ }^{27}$.

3. A juicio del máximo tribunal, la solidaridad establecida en el artículo 183 B CT no alcanzaría a las obligaciones de hacer, tales como la infracción al deber de seguridad que tiene el contratista sobre sus propios trabajadores, según lo dispuesto en el artículo 184 del CT. El artículo 183 E consagra a juicio de la Corte, una obligación directa y subjetiva que le impone el mencionado artículo y que consiste en el deber de protección de la empresa principal respecto de los trabajadores que prestan servicios en su faena.

\footnotetext{
LANATA (2011) 348 y ss.

Corral (2010) 19.

Nuevamente, cabe advertir al lector que la Corte Suprema volvió a unificar los artículos 183-B y 183-E del Código del Trabajo. En efecto, y a propósito de la indemnización por daño moral por accidente de trabajo, señaló la procedencia del estatuto de la solidaridad entre la empresa principal y el contratista, en atención a los esenciales principios que inspiran al derecho del trabajo; así como la naturaleza de esta obligación indemnizatoria, que a juicio del tribunal, sería de aquellas de dar.
} 
4. También y en relación al artículo $183 \mathrm{E}$, quedan abiertas dos interrogantes: el estatuto de responsabilidad aplicable a la empresa principal por incumplir su deber de cuidado respecto de todos los trabajadores que prestan servicio en su obra o faena y la eventual incompetencia de los juzgados del trabajo para conocer de la responsabilidad que le cabe a esta frente a dicho incumplimiento. 